\title{
Measuring and monitoring quality of care in family planning: are we ignoring negative experiences?
}

This article was published in the following Dove Press journal:

Open Access Journal of Contraception

26 May 2016

Number of times this article has been viewed

\author{
Shannon Harris' \\ Laura Reichenbach ${ }^{2}$ \\ Karen Hardee ${ }^{2}$ \\ 'Public Health Consultant, Seattle, \\ WA, USA; ${ }^{2}$ The Evidence Project, \\ Population Council, Washington, DC, \\ USA
}

\begin{abstract}
Despite decades of emphasis on quality of care, qualitative research continues to describe incidents of poor quality client-provider interactions in family planning provision. Using an emerging framework on disrespect and abuse (D and A) in maternal health services, we reviewed the global published literature for quantitative tools that could be used to measure the prevalence of negative client experiences in family planning programs. The search returned over 7,000 articles, but only 12 quantitative tools included measures related to four types of $\mathrm{D}$ and $\mathrm{A}$ (non-confidential care, non-dignified care, non-consented care, or discrimination). We mapped individual measurement items to D and A constructs from the maternal health field to identify measurement gaps for family planning. We found significant gaps; current tools are not adequate for determining the prevalence or impact of negative client experiences in family planning programs. Programs need to invest in tools that describe all aspects of client experiences, including negative experiences, to increase accountability and maximize the impact of current investments in family planning programs.
\end{abstract}

Keywords: quality of care, family planning programs, disrespect and abuse, client-provider interactions

\section{Introduction}

Since the landmark fundamentals of quality of care (QOC) framework, published by Bruce, ${ }^{1}$ family planning programs have sought to ensure that clients have access to quality information and services. The QOC framework defines quality along six dimensions that represent both technical program elements and interpersonal relations between family planning providers and clients. Efforts to improve family planning quality aim to ensure that clients are able to voluntarily choose their family planning method, have a positive experience so that they continue their method (or switch to another desired method), and recommend the services to others. QOC has been found to be a determinant of family planning uptake and continuation. ${ }^{2-8}$

Despite the long-held programmatic focus on QOC, coercion and allegations of coercion have been a matter of concern to family planning programs for decades. ${ }^{9}$ Qualitative research has revealed that some clients experience poor quality care while accessing family planning services, including negative client-provider interactions (CPIs). ${ }^{10-13}$ Schuler and Hossain ${ }^{10}$ found that women in rural Bangladesh sometimes had to beg for services, while Tumlinson et $\mathrm{al}^{11}$ found that women in Kenya were at times ignored, berated, or charged unauthorized fees for services. The experiences of these women are described in qualitative studies, but there are no data on the prevalence of 
these negative experiences in broader programs, making it impossible to examine the impact of negative client experiences on family planning uptake and continuation.

CPI is a key element of quality in family planning and other health programs. In health care decisions, client participation increases their investment in a treatment course. ${ }^{14}$ $\mathrm{Kim}^{15}$ found that when nurses are professionally trained to provide quality counseling, clients are more likely to return for follow-up visits. Simmons and Elias ${ }^{16}$ state that "studying client-provider interaction revolutionizes our thinking about programs [...] Ignorance of client-provider interaction is ignorance of the centerpiece of programs". Murphy ${ }^{17}$ outlines best practices in CPI, including treating clients well, respecting privacy, and tailoring counseling to individual client needs. Further understanding of negative CPI is critical to our understanding of women's experience with family planning programs and whether their rights are respected when they go to access services. ${ }^{18,19}$

The importance of assuring positive CPI as a part of QOC to enhance program outcomes is also well established in the literature, ${ }^{2,4,16}$ and the linkage between QOC and method continuation is very strong. ${ }^{5}$ Tumlinson et $\mathrm{al}^{8}$ found that being treated very well by providers had the highest correlation with contraceptive use among different aspects of QOC for young women. However, negative experiences have a detrimental impact on family planning program success. ${ }^{5}$ Developing measurement indicators and methodologies that capture the full range of client experiences and describe the variety of CPIs can provide important data for program accountability and to inform the fulfillment of global commitments to prevent coercion and respect rights in family planning programs. The family planning field needs validated measures of prevalence of negative CPIs to learn to what extent negative experiences influence family planning uptake and continued use. This paper examines whether the measures currently used in family planning programs to measure QOC are sufficiently capturing and describing the frequency and impact of negative CPIs. It does this through the application of a recent approach developed in maternal health to measure disrespect and abuse (D and A) in delivery services.

Recently, there have been attempts to better describe negative client experiences in maternity care and how they relate to women's maternity care seeking behaviors. ${ }^{20-24}$ This work has included an assessment of D and A in facility-based maternity care, including types of abuse, underlying factors contributing to abuse, potential interventions to change practice, and identified gaps in research related to D and $\mathrm{A}$ in maternal health care. ${ }^{25}$ The assessment resulted in a $\mathrm{D}$ and A framework for maternity care that includes seven types of disrespectful and abusive care: non-consented care, non-dignified care, non-confidential care, physical abuse (including sexual abuse), detention in facilities, abandonment, and discrimination. Freedman et $\mathrm{al}^{22}$ used the seven types of $\mathrm{D}$ and $\mathrm{A}$ described by Bowser and $\mathrm{Hill}^{25}$ to define D and A along a continuum of interpersonal D and A to systemic $\mathrm{D}$ and $\mathrm{A}$ to better capture the range of types and causes of $\mathrm{D}$ and $\mathrm{A}$. The original D and A framework did not include definitions that would enable measurement of different types of $\mathrm{D}$ and $\mathrm{A}$; the Freedman et al continuum allows definitions of $\mathrm{D}$ and $\mathrm{A}$ to be developed that can then be used to monitor the prevalence of negative experiences in maternal health and other health programs. This work is part of a growing global trend to reveal and discuss D and A in medical settings. ${ }^{26}$

The explicit approach that maternal health has taken to clearly describe different types of D and A and how they occur in the health system may be useful for informing family planning programs' assessment of QOC, including CPI. The family planning field has used the QOC framework to develop standards of quality to monitor in programs. The framing of this monitoring has been to measure positive aspects of quality or progress toward the desired state of quality in programs, but generally has not included specific measures to highlight negative client experiences. We hypothesize that negative client experiences are left to conjecture using our existing monitoring frameworks.

This paper reviews existing measurement and monitoring tools in family planning through the lens of the Bowser and Hill framework ${ }^{25}$ of $\mathrm{D}$ and $\mathrm{A}$ in maternity care to understand the extent to which negative client experiences can be measured with existing tools. Through this review and analysis, we describe how gaps in existing family planning measurement tools may render negative experiences invisible, making it impossible to know how frequently women are exposed to negative care and how it affects their family planning utilization. The paper also discusses implications of developing new tools that can monitor negative client experiences to better inform programs.

\section{Methods}

The analysis in this paper is part of a larger systematic review to identify existing measures and indicators of D and A from other health services to inform the current discussion about measurement of D and A in maternity care. ${ }^{27}$ This paper draws solely on the review of the literature on family planning from that larger systematic review on D and A.

The term family planning was searched in combination with each of the seven types of D and A described in the maternal health field (non-consented care, non-dignified care, 
non-confidential care, physical abuse, detention in facilities, abandonment, and discrimination) in SCOPUS, PubMed, and CINAHL. The search was not bound by time or geographic location to capture the widest range of tools possible. The initial search returned 7,124 articles. Any tools and articles related to abortion services were eliminated (see URC-CHS TRAction Project report, forthcoming, for a detailed account of the search methodology and inclusion criteria). ${ }^{27}$ The main inclusion criterion was that the article included a quantitative tool (a data collection instrument that collects information that can be analyzed quantitatively) that captured one or more aspects of the D and A framework. Given the importance of the term coercion in family planning, this term was also included explicitly in the search. A total of 18 articles met the inclusion criteria for further review (Table 1).

For this analysis, we included measures for four of the seven types of disrespectful and abusive treatment described in the D and A framework: non-consented care, non-dignified care, non-confidential care, and discrimination. These four types were selected because we determined they had the highest potential to occur in family planning service provision. The other three types of D and A, namely, detention in facilities, physical abuse, and abandonment were not included because, as described in Bowser and Hill, ${ }^{25}$ they seem unlikely to occur in family planning programs. For the purposes of this paper, forced sterilizations and similar coercive practices are categorized as non-consented care, although they could also be regarded as physical abuse.

Based on this narrowed criteria, 11 of the 18 articles were included in the analysis for this paper. In addition, the PMA2020 survey, ${ }^{28}$ which provides annual monitoring of family planning programs for FP2020, was included in the analysis because of its central role in current family planning monitoring efforts.

The D and A framework developed by Bowser and Hill ${ }^{25}$ provide examples of actions that are disrespectful and abusive in the context of maternity care; it does not, however, provide definitions for each of the seven D and A constructs. In order to link family planning measurement tools with specific types of $\mathrm{D}$ and $\mathrm{A}$, we developed operational definitions of the four $\mathrm{D}$ and $\mathrm{A}$ constructs included in the analysis, drawing from Bowser and $\mathrm{Hill}^{25}$ and other published sources and examples (these definitions were developed prior to the publication of the Freedman et al framework and focus on interpersonal interactions, not system factors that contribute to D and A).

\section{Non-consented care (including coercion)}

Drugs or procedures are administered without client's knowledge or without expressed permission; clients are not provided full and accurate information about the drug or procedure that is administered. Clients are also not given an opportunity to choose among other available options; they are not given the opportunity to opt out of receiving a procedure or drug. Consent must relate to the treatment, be informed, be given voluntarily, and not be obtained through misrepresentation or fraud. ${ }^{29}$ Relatedly, coercion in family planning consists of actions or factors that compromise individual autonomy, agency or liberty in relation to contraceptive use, or reproductive decision making through force, violence, intimidation, or manipulation. ${ }^{9}$

\section{Non-dignified care}

Clients experience humiliating treatment such as yelling, name-calling, threatening, scolding, or being insulted. Clients experience psychological abuse such as being ignored when asking for help, are told inaccurate information to frighten or shame them, or are disempowered by a provider through disregard of the client's requests or preferences.

\section{Non-confidential care}

Services are provided without visual or auditory privacy. Clients' information is not kept confidential either by staff or providers discussing clients' condition or choices or because systems are not in place to ensure that client records will be kept confidential. ${ }^{30}$

\section{Discrimination}

Clients experience differential treatment on the basis of personal characteristics (such as ethnicity, socioeconomic status, age, marital status, family status, sex, and disability), which puts some clients at a disadvantage (adapted from National Research Council). ${ }^{31}$ Stigma, considered in some sexual and reproductive health fields as a more subtle form of discrimination, is not explicitly mentioned in the work on $\mathrm{D}$ and $\mathrm{A}$ and maternity care; hence, it was not included in the search strategy.

For analysis, we reviewed each measurement item in each of the 12 tools to determine whether any related to the four constructs could be used to measure prevalence of the construct in family planning. As part of the analysis, we also identified gaps in the information that family planning programs can gather on negative experiences of women using existing tools.

\section{Results}

The 12 tools that were reviewed included items related to the four types of D and A (non-consented care and coercion, non-dignified care, non-confidential care, and discrimination), but significant gaps remain (Table 2). 


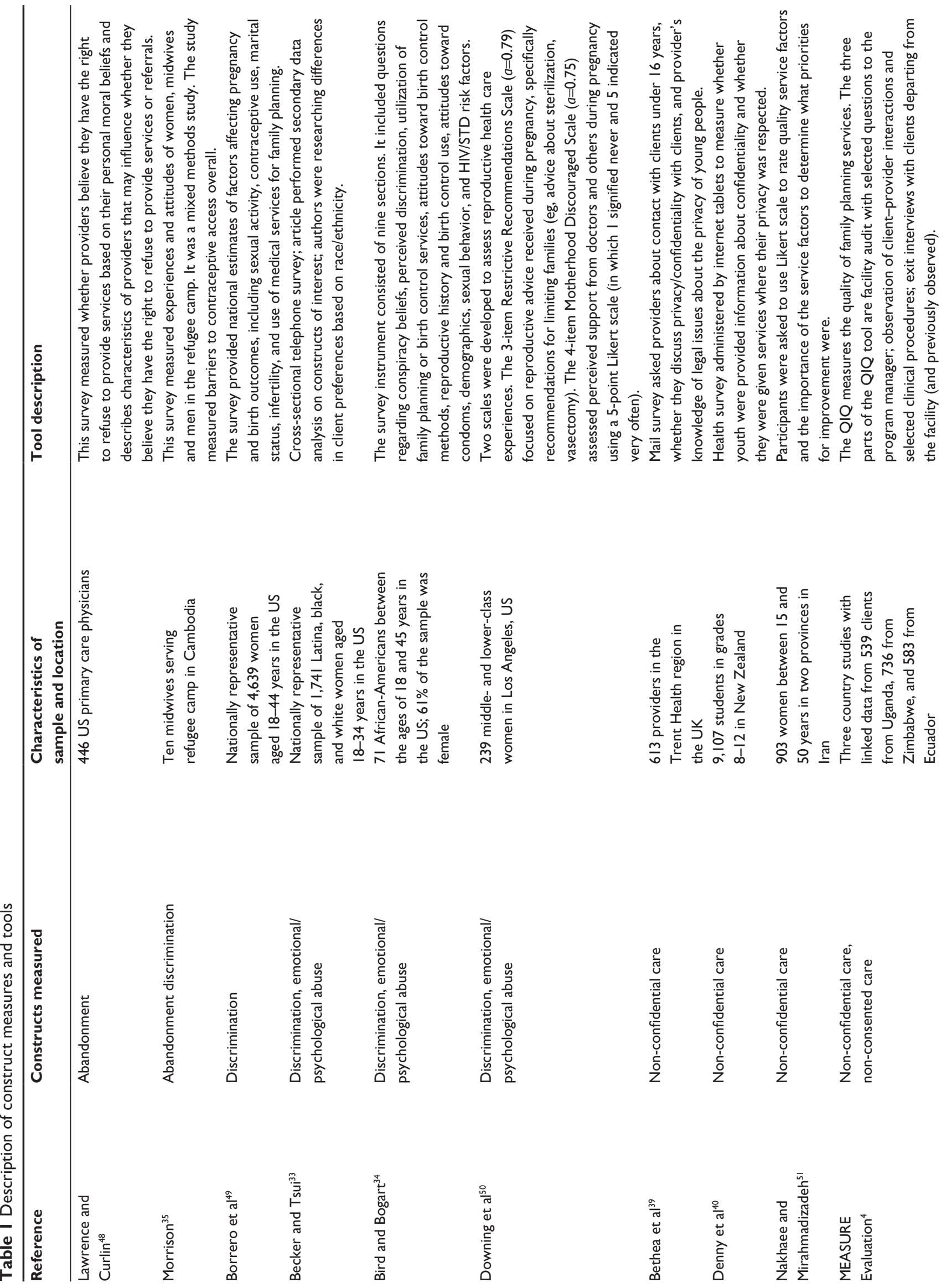



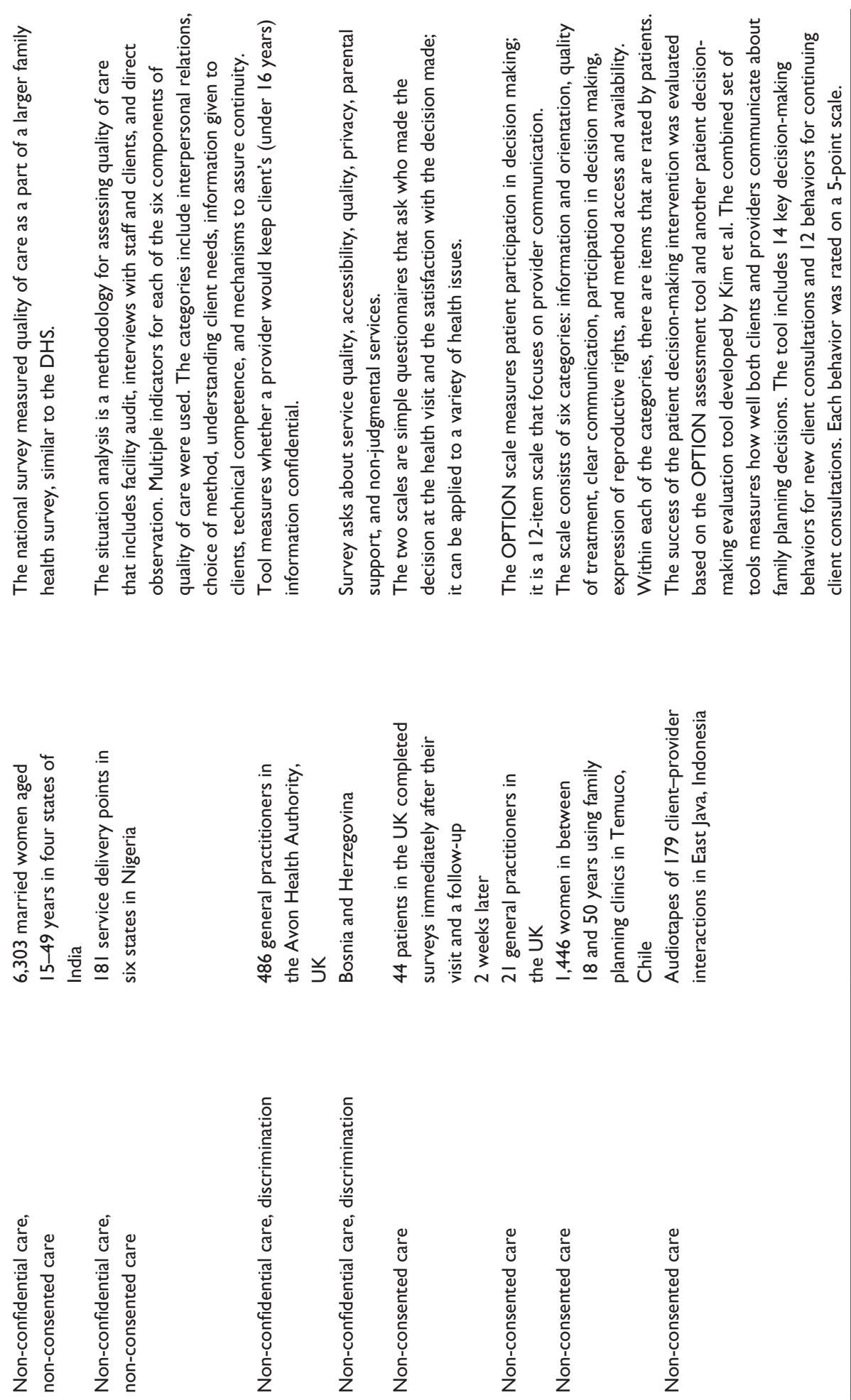

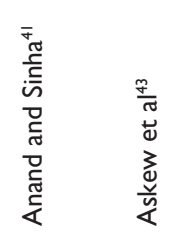

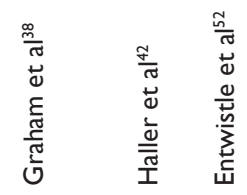

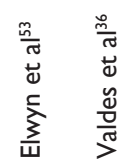

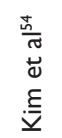


Table 2 Gaps in measuring $D$ and $A$ in family planning

\begin{tabular}{lll}
\hline$D$ and $A$ constructs (from & Measure(s) & Tools, indicators, and survey questions \\
Bowser and $\mathrm{Hill}^{25}$ ) & $\begin{array}{l}\text { exists in a validated } \\
\text { assessment tool }\end{array}$
\end{tabular}

assessment tool

\section{Non-consented care}

- Client receives procedure or method without her knowledge or consent

- Clients are not given other options Yes

- Clients are not given full or accurate information Yes

- Clients do not decide for themselves what Yes method to use

- Clients choose to use their family planning method without force, violence, intimidation, or manipulation

\section{Non-dignified care}

- Clients experience humiliating treatment such

- Clients experience psychological abuse such

- Clients are disempowered by the provider

\section{Non-confidential care}

- Client services are provided with visual as yelling, name calling, threatening, scolding, or being insulted as being shamed or ignored

- Clients are told inaccurate information to frighten, coerce, or shame them or staff or auditory privacy

- Systems are in place to ensure that client is assured of confidentiality and that records will be kept confidential
No tool identified in the review

Clients told of other methods (PMA2020 indicators)

Clients were counseled on side effects (PMA2020 indicators)

Clients were told of other methods (PMA2020 indicators)

Clients chose family planning method alone or jointly (PMA2020 indicators)

Survey questions: Have you ever felt pressured by someone at a clinic or doctor's office to use or continue to use a particular method of birth control when you would have rather used another method or no method at all? ${ }^{33}$

A doctor or nurse strongly encouraged you to use one method of birth control when you preferred another ${ }^{34}$

No tool was identified in this review

Survey questions: You felt like the doctor or nurse was not listening to what you were saying

A doctor or nurse assumed you were on welfare

A doctor or nurse assumed you had multiple sexual partners

A doctor or nurse assumed you had a sexually transmitted disease such as chlamydia, gonorrhea, genital warts, herpes, and $\mathrm{HIV}^{34}$

During your pregnancy how often did you feel like your doctor did not want you to have a baby or the doctor tried to persuade you not to have a child? ${ }^{50}$

No tool identified in this review

Identified percent of women denied contraceptives by midwives ${ }^{35}$ Identified number of midwives who would not provide contraceptives to particular women by characteristic and family planning method ${ }^{35}$ Illustrative indicators where negative responses may relate to nondignified care:

Feeling of being listened to by the health care provider

Providers are willing to explain methods

Providers are willing to answer questions

Providers answer questions politely ${ }^{36}$

Provider sees client in private ${ }^{4}$

Survey questions: Did the staff respect your need for privacy? ${ }^{41}$

Privacy - auditory privacy for counseling; visual privacy for

examination $^{43}$

Did you spend time with the provider without an accompanying adult? ${ }^{42}$ Talking with the nurse is done in a way that no one else can hear ${ }^{42}$ In the last 12 months, did you get a chance to talk to a doctor or other health provider privately? (Meaning one on one - without your parents or other people in the room $)^{40}$

If a 14 year old requested emergency contraception from you whom, if anyone, would you routinely inform ? $^{38}$

Yes Assurance to client of privacy ${ }^{39}$

Awareness of legality of keeping youth client information private ${ }^{39}$ 
Table 2 (Continued)

\begin{tabular}{|c|c|c|}
\hline $\begin{array}{l}\text { D and A construct (from } \\
\text { Bowser and } \text { Hill }^{25} \text { ) }\end{array}$ & $\begin{array}{l}\text { Measure(s) } \\
\text { exists in a validated } \\
\text { assessment tool }\end{array}$ & Notes \\
\hline $\begin{array}{l}\text { - Client perceives information will be kept } \\
\text { confidential }\end{array}$ & Yes & $\begin{array}{l}\text { Client believes provider will keep her information confidential }{ }^{4} \\
\text { Were you provided information about confidentiality }{ }^{42} \\
\text { Were you convinced your information would be kept confidential? }{ }^{42} \\
\text { Do you trust that information given at this clinic will be kept } \\
\text { confidential? } \\
\text { In the last } 12 \text { months, did a doctor or other health provider tell you } \\
\text { that what you talked about with them was confidential? (Meaning it } \\
\text { would not be shared with anyone else) }{ }^{40}\end{array}$ \\
\hline Discrimination & & \\
\hline $\begin{array}{l}\text { - Client experiences differential treatment on } \\
\text { the basis of a personal characteristic that } \\
\text { disadvantages the client }\end{array}$ & Yes & $\begin{array}{l}\text { You were treated with less courtesy than other people } \\
\text { You were treated with less respect than other people } \\
\text { You received poorer service than other people }{ }^{34}\end{array}$ \\
\hline
\end{tabular}

\section{Non-consented care}

Current measures exist that help programs and donors know whether women are given information on multiple contraceptive methods, whether they receive counseling on side effects, and whether they participated in making the decision about the contraceptive they use. There are no monitoring tools or studies that have attempted to learn how many women have received a contraceptive method without consent or through coercive means. The PMA2020 annual survey provides information about whether women are given a choice of methods, provided information about side effects, and whether they chose their family planning method alone or jointly. ${ }^{32}$ However, if a woman reports that she did not choose her method of contraception alone or jointly, we do not know what caused her to use a method she did not choose.

Another gap in measuring non-consented care is whether clients were pressured to adopt a method that they did not want. The two tools we found related to non-consented care have only been used in the US. Becker and Tsui ${ }^{33}$ included a question about pressure to use a contraceptive method in their survey of low-income women in the US. Their results indicate that $11 \%$ of black women experienced pressure to use a method of contraception, while $5 \%$ of white and English-speaking Latina women felt the pressure. The validated question on this survey could be used in other locations and contexts to measure whether family planning clients elsewhere experience pressure to use a method or a particular method of family planning. Similarly, Bird and Bogart $^{34}$ asked women if they were strongly encouraged to use a particular method of contraception when they preferred another. Such questions begin to reveal whether and how women experience non-consented care when accessing family planning services, but additional tools and studies are needed.

\section{Non-dignified care}

Non-dignified care was included in the analysis because it is hypothesized that non-dignified care has a negative influence on women's experience with family planning, including being a deterrent to family planning uptake and continuation. Existing tools capture some aspects of non-dignified care. One tool asked about providers' assumptions about clients and clients' perceptions of being listened to. ${ }^{34}$ Two tools assessed actions that could disempower patients such as providers denying methods to women based on particular characteristics (eg, parity, age, health status) and providers' unwillingness to engage in discussion with clients. ${ }^{35,36}$ The tools used in a study by Valdes et $\mathrm{al}^{36}$ phrase indicators positively (eg, provider answers questions politely) so that a no response indicates that the client may have had a negative experience. The tools do not describe a method for probing when a client answers negatively, but these measures could be augmented with such probing questions that allow clients to provide detailed descriptions of their experience when necessary.

While no family planning measurement tools were identified that measure humiliating treatment such as name calling or scolding, there are incidents reported in the literature in which women who were coerced into consenting to sterilization described experiencing humiliating treatment. ${ }^{13}$ Many qualitative studies describe non-dignified treatment. ${ }^{10-12}$ In a study by Schuler et al, ${ }^{37}$ simulated clients in Nepal describe degrading treatment by providers to lower-class clients. This article describes social patterns in which providers promote traditional pronatalist norms and pressure clients to conform. 
While not a recent article, Schuler et al's ${ }^{37}$ work provides insight into issues that may arise as family planning services are scaled up before societal norms have time to change. No articles specifically asked about the provision of misinformation, although providers may omit information about a method to promote uptake of a particular provider preferred method. Because there are reports of shaming and humiliating treatment in the literature, ${ }^{10,13}$ family planning programs may benefit from learning the extent to which this type of treatment occurs and its impact on women's care seeking behavior in family planning programs.

\section{Non-confidential care}

Maintaining confidentiality and privacy increases the comfort level of clients, contributes to a trusting relationship between client and provider, and is necessary for respecting and protecting the rights of clients. The tools found in this review measured privacy and confidentiality by asking the providers about their knowledge or practice of respecting privacy and confidentiality, ${ }^{38,39}$ asking the client whether they were assured of confidentiality or experienced privacy during service delivery, ${ }^{39-42}$ whether they trust that confidentiality will be maintained, ${ }^{4,42}$ or by observing that conditions support privacy and confidentiality., ${ }^{4,43}$ Based on this review, there appears to be adequate tools and indicators to measure privacy and confidentiality in family planning services from both provider and client perspectives.

\section{Discrimination}

Discrimination was included because often those who are affected most by negative treatment by providers are minorities and vulnerable groups. ${ }^{13,44,45}$ One tool was found that gathers information on client perception of discrimination and was used in the US in a study measuring birth control conspiracy beliefs and perceived discrimination among African-Americans. ${ }^{34}$ There are significant challenges to measure discrimination such as measuring only perceived discrimination and linking discrimination to negative outcomes. ${ }^{31}$ Although perceived discrimination may overreport or under-report actual discrimination, it is a relevant measure for family planning because clients' experience will inform their care seeking behavior, including uptake and continuation of family planning. Additional measures are needed to gain more knowledge about client experiences of discrimination.

\section{Discussion}

Through this review of the existing family planning literature related to a D and A framework in maternity care, we identified tools with measures that explore some negative experiences of clients related to family planning. However, our review also found that family planning monitoring tools related to QOC are oriented to report how many clients have positive experiences (eg, percentage of women greeted respectfully, percentage of women who were assured of confidentiality) or how programs are measuring up to a particular standard. Current family planning assessment tools clearly play an important role in promoting a high standard of quality. While these tools are very helpful in monitoring and shaping how programs perform and are appropriate for routine monitoring, they do not adequately describe variations of client experience and may inadvertently deemphasize measurement of negative client experiences, including coercion.

For example, the five PMA2020 country briefs that had been published as of February 16, 2015 (Ghana, Ethiopia, Democratic Republic of Congo, Kenya, and Uganda) show that the majority of women, between $80 \%$ and $90 \%$, choose their family planning method themselves or jointly. ${ }^{32}$ This statistic may minimize the implication that between 1 in 5 and 1 in 10 current users of family planning in these countries reported that they did not choose their family planning method themselves or jointly with their provider or partner. To improve programming, it is important to know what occurred that caused them to use a contraceptive method they did not participate in choosing and the impact of that experience on their satisfaction with their method.

The PMA2020 monitoring tools ask whether the method a woman is using was chosen by her, jointly by her along with the provider or partner, or solely by her provider or partner, but disaggregation by the role of the provider or partner is not routinely reported. This obfuscates what programming adjustments may be required to ensure that women have agency when choosing their method and whether the focus needs to be on the interaction with her partner or provider. This is one particular example of how the lack of specificity in family planning program measures may hamper the design of appropriate interventions to improve QOC.

In addition to reporting, the question about who decided about the method could be followed up with questions that ask whether the client is satisfied with her method, if she felt pressured to use the method, and whether she has positive (or negative) feelings about her family planning service experience. It is important to learn whether these women are satisfied with their method choice and with the decision-making process because some women may be most comfortable deferring such decisions to their provider or partner. 
Although current tools can indicate that a client did not have a positive experience with family planning services if they provide a negative response, the tools reviewed did not include probing questions or additional follow-up to explore those negative responses in more depth. The field remains in need of these more in-depth tools, especially as services are being scaled up to meet FP2020 goals.

Another argument for including measures of negative treatment is to promote accountability within programs. Becker and Tsui's ${ }^{33}$ tool includes the only question that directly asks about an aspect of coercion in family planning (ie, pressure to use a method despite client's lack of desire), but it was used in a US-based study and was not linked to a particular clinic or program. Facility-based monitoring tools could be developed so that interventions can be implemented to achieve respectful, quality treatment.

Monitoring and accountability have received increasing attention in relation to FP2020, with two projects devoted to monitoring progress in reaching the FP2020 goal (www. PMA2020.org; www.track20.org). Monitoring priorities include measuring changes in access and use, equity in access, program reach, and method availability while continuing to measure key family planning indicators such as $\mathrm{CPR}$, unmet need, total demand, and fertility. Although there has been a conscious decision to include measures related to voluntarism and choice more systematically, measures that capture negative experiences can be sensitive and have methodological challenges, thus making them more difficult to prioritize among the many other measurement needs. Data that may implicate family planning programs in wrongdoing have been used by family planning detractors to press for de-funding programs, for example, as happened in both Bangladesh and Timor-Leste in the 1980s and 1990s, respectively. ${ }^{9}$ The possibility that sensitive program data can be misused in this way decreases the incentive to proactively monitor for negative treatment in family planning. However, a solid and comprehensive monitoring program allows programs to anticipate emerging issues and provides assurance of QOC for clients; so despite the challenges, we still need to collect this kind of data.

As definitions and constructs are defined, methodological challenges will remain. Client experience is subjective, and perception of treatment may change over time. What one woman may find humiliating or offensive, another woman may not experience as troubling. Freedman et al's ${ }^{22}$ framework addresses this by noting that there are actions that all would agree qualify as D and A, while other actions would be considered $\mathrm{D}$ and $\mathrm{A}$ by some but not all clients or providers. The clients' perception and satisfaction with their experience must be central to measurement so that problems are not inferred when there are none from a client perspective. This also needs to be balanced with the knowledge that some women will be oblivious to program structures that impinge on their right to make full, free, and informed choices about family planning. Separating how a woman was treated from her satisfaction with a particular outcome is also important. In recent reports of women being pressured or forced to be sterilized in the US prison system, at least one woman expressed relief that she now does not have to worry about pregnancy. ${ }^{46} \mathrm{Her}$ satisfaction with sterilization does not justify the coercive and disrespectful treatment the inmates received.

During this time of increased funding toward achievement of ambitious family planning goals, multiple efforts are being undertaken to ensure that clients have access to high quality, voluntary family planning through increased monitoring and quality improvement efforts. ${ }^{32}$ With this re-emphasis on family planning programs, we have an opportunity to revolutionize programs by taking a closer look at CPIs and gain a greater understanding of client-centric factors that influence program success.

The additional investment in monitoring and accountability provides an opportunity to learn more about the impact of client experience on client well-being and program outcomes. Specific questions would allow us to learn more about the impact of client experience on uptake and continuation and could provide feedback to inform and improve programming. Questions that cannot be addressed with the current measures identified in this study, but should be of interest to family planning programs, include the following:

1. What factors contribute to a family planning client reporting that she did not make the decision to adopt a family planning method herself?

2. How many clients do not pursue family planning services because of their own or others' negative experiences with providers? How frequently does the age of the client, particularly young clients, contribute to negative experiences with providers?

3. How many clients have experienced humiliating treatment, abuse of power by a provider, or poor technical quality during the insertion or removal of long-acting, reversible methods?

To adequately answer these questions, family planning programs need to be able to describe and identify instances of poor quality care, including the concepts from the $\mathrm{D}$ and $\mathrm{A}$ framework, namely, non-consented care (including coercion), non-dignified care, non-confidential care, and discrimination, to track both desirable and undesirable family planning 
outcomes. Additional development of measures and tools is needed so that agreement can be reached on what and how to measure these experiences.

All the tools identified in this review, other than the PMA2020 tool, were identified though a strict search strategy, which may have left out key resources. The search focused on published articles and did not include a systematic search of monitoring or measurement tools that may be used to monitor programs by various organizations. Furthermore, because the review focused on the published literature that may be less likely to publish negative findings, including experiences of $\mathrm{D}$ and $\mathrm{A}$, this review likely does not reflect the extent to which clients have negative family planning experiences. It also does not reflect the work that programs do to address issues that arise ad hoc, such as client complaints, as part of routine service delivery. Family planning programs may have methods to ensure quality, such as the Choice Project's ${ }^{47}$ quality counseling assurance protocol, but focus on provider's behavior rather than women's experience. This review focused on identifying quantitative measures of $\mathrm{D}$ and A constructs and did not describe the types of analysis that could be carried out with current measures, such as detection of discrimination through analysis of responses from different demographic groups. This review provides the starting point for further work to describe the analytic approaches that are possible. Qualitative measures or approaches to identifying and describing D and A were also not presented here; this is an important area for future work. Finally, the review included a range of tools including clinic- and population-based instruments, some of which may not be suited for regular monitoring of programs.

\section{Conclusion}

The lack of measurement tools that capture negative experiences has resulted in limited data on how many women have these experiences, how coercion happens in different contexts, or how these experiences affect program outcomes. These significant knowledge gaps make it difficult to assure accountability for voluntarism, and if problems arise, to develop interventions and redress mechanisms to address them. Tools that capture negative experiences should be designed so that they lead to program improvement, not punishment. There are currently very few accessible systems for accountability and redress. ${ }^{9,55}$ It will remain very difficult to ensure accountability if problematic issues such as disrespectful and abusive treatment, including coercion, are not adequately described and measured and there is no agreement on how to identify, measure, monitor, and respond when issues arise. If these issues are not recognized and addressed promptly in programs, women's well-being as well as the reputation of family planning methods and programs are at risk.

\section{Acknowledgments}

The authors would like to thank the USAID-funded TRAction Project at URC-CHS and in particular Tiffany Clark, Cara Pasquale, Maria Escalante, and Emily Peca for their work and collaboration on the larger systematic review to identify existing measures and indicators of $\mathrm{D}$ and $\mathrm{A}$ from other health services to inform the current discussion about measurement of $\mathrm{D}$ and $\mathrm{A}$ in maternity care. The authors also thank Anrudh Jain for his comments on an earlier draft of the manuscript. The manuscript benefitted from the feedback at the Population Association of America Meeting held in San Diego, California, US, in May 2015, where it was presented as a poster presentation. The Evidence Project is made possible by the generous support of the American people through the United States Agency for International Development (USAID) under the terms of cooperative agreement no. AIDOAA-A-13-00087. The contents of this manuscript are the sole responsibility of the Evidence Project and Population Council and do not necessarily reflect the views of USAID or the United States Government.

\section{Disclosure}

The authors report no conflicts of interest in this work.

\section{References}

1. Bruce J. The fundamental elements of Quality of Care: a simple framework. Stud Fam Plann. 1990;21(2):61-91.

2. Jain AK. Fertility reduction and the quality of family planning services. Stud Fam Plann. 1989;20(1):1-16.

3. Simmons R, Phillips JF. The proximate operational determinants of fertility regulation behaviour. In: Phillips JF, Ross JA, eds. Family Planning Programs and Fertility. New York: Oxford University Press; 1992:181-201.

4. MEASURE Evaluation. Quick Investigation of Quality (QIQ). A user's guide for monitoring quality of care in family planning. MEASURE Evaluation Manual Series, No. 2. MEASURE Evaluation. Carolina Population Center, University of North Carolina at Chapel Hill; 2001.

5. Blanc AK, Curtis SL, Croft TN. Monitoring contraceptive continuation: links to fertility outcomes and quality of care. Stud Fam Plann. 2002;33(2):127-140.

6. Jain AK, Ramarao S, Kim J, Costello M. Evaluation of an intervention to improve quality of care in family planning programme in the Philippines. J Biosoc Sci. 2012;44(1):27-41.

7. Minnis AM, Mavedzenge SN, Luecke E, Dehlendorf C. Provider counseling to young women seeking family planning services. Perspect Sex Reprod Health. 2014;46(4):223-231.

8. Tumlinson K, Pence BW, Curtis SL, Marshall SW, Speizer IS. Quality of care and contraceptive use in urban Kenya. Int Perspect Sex Reprod Health. 2015;41(2):69-79. 
9. Hardee K, Harris S, Rodriguez M, et al. Achieving the goal of the London Summit on Family Planning by adhering to voluntary, rights-based family planning: What can we learn from past experiences with coercion? Int Perspect Sex Reprod Health. 2014;40(4): 206-214.

10. Schuler SR, Hossain Z. Family planning clinics through women's eyes and voices: a case study from rural Bangladesh. Int Fam Plann Perspect. 1998;24(4):170-175.

11. Tumlinson K, Speizer IS, Archer LH, Behets F. Simulated clients may reveal factors that may limit contraceptive use in Kenya. Glob Health Sci Pract. 2013;1(3):407-416.

12. Nalwadda G, Mirembe F, Tumwesigye NM, Byamugisha J, Faxelid E. Constraints and prospects for contraceptive service provision to young people in Uganda: providers' perspectives. BMC Health Serv Res. 2011:11:220.

13. Open Society Foundation. Against Her Will: Forced and Coerced Sterilization of Women Worldwide. OSF; 2011:12.

14. Kim YM, Kols A, Bonnin C, Richardson P, Roter D. Client communication behaviors with healthcare providers in Indonesia. Patient Educ Couns. 2001;45(1):59-68.

15. Kim YM, Rimon J, Winnard K, et al. Improving the quality of service delivery in Nigeria. Stud Fam Plann. 1992;23(2):118-127.

16. Simmons R, Elias C. The study of client-provider interactions: a review of methodological issues. Stud Fam Plann. 1994;25(1):1-17.

17. Murphy ND. Best Practices in Client-Provider Interactions in Reproductive Health Services: A Review of the Literature. Washington, DC: Population Reference Bureau. Available from: http://www.prb.org/pdf/ NewPerspQOC-LitRev.pdf. Accessed July 31, 2014.

18. Erdman JN, Cook RJ. Reproductive Rights. International Encyclopedia of Public Health. Kris editor. Oxford: Oxford Academic Press; 2008:532-538.

19. WHO. Ensuring Human Rights in the Provision of Contraceptive Information and Services. Geneva: WHO; 2014.

20. Freedman LP, Kruk ME. Disrespect and abuse of women in childbirth: challenging the global quality and accountability agendas. Lancet. 2014;384(9948):e42-e44.

21. McMahon SA, George AS, Chebet JJ, Mosha IH, Mpembeni RN, Winch PJ. Experiences of and responses to disrespectful maternity care and abuse during childbirth: a qualitative study with women and men in Morogoro Region, Tanzania. BMC Pregnancy Childbirth. 2014;14:268-281.

22. Freedman L, Ramsey K, Abuya T, et al. Defining disrespect and abuse of women in childbirth: a research, policy and rights agenda. Bull World Health Organ. 2014;92(12):915-917.

23. Warren C, Njuki R, Abuya T, et al. Study protocol for promoting respectful maternity care initiative to assess, measure and design interventions to reduce disrespect and abuse during childbirth in Kenya. BMC Pregnancy Childbirth. 2013;13(1):21.

24. Abuya T, Warren CE, Miller N, et al. Exploring the prevalence of disrespect and abuse in childbirth in Kenya. PLOS One. 2015; 10(4): $\mathrm{e} 0123606$

25. Bowser D, Hill K. Exploring Evidence for Disrespect and Abuse in Facility-based Childbirth: Report of a Landscape Analysis. Cambridge, MA: Harvard School of Public Health University Research Corporation, LLC; 2010.

26. Anonymous. Our family secrets. Ann Intern Med. 2015;163(4):321.

27. URC-CHS TRAction Project Systematic Review of Disrespect and Abuse Report, Forthcoming.

28. Performance Monitoring and Accountability 2020. Glossary of Family Planning Indicators. Available from http://www.PMA2020.org/ Glossary-family-planning-indicators. Accessed February 23, 2016.

29. Government of Ontario, Canada. Health Care Consent Act 1996. Available from: http://www.e-laws.gov.on.ca/html/statutes/english/ elaws_statutes_96h02_e.htm\#BK1. Accessed August 22, 2014.

30. De Bord J, Burke W, Dudzinsky, DM. 2013. Ethics in medicine: confidentiality. University of Washington School of Medicine. Available from: http://depts.washington.edu/bioethx/topics/confiden.html. Accessed August 17, 2014.
31. National Research Council. Measuring Racial Discrimination. Washington, DC: National Academies Press; 2004.

32. Performance Monitoring and Accountability 2020. Publications: family planning briefs. PMA2020.org/publications. Available from http://www. pma2020.org/publications. Accessed February 22, 2015.

33. Becker D, Tsui AO. Reproductive health service preferences and perceptions of quality among low-income women: racial, ethnic and language group differences. Perspect Sex Reprod Health. 2008;40(4):202-211.

34. Bird ST, Bogart LM. Birth control conspiracy beliefs, perceived discrimination, and contraception among African Americans: an exploratory study. $J$ Health Psychol. 2003;8(2):263-276.

35. Morrison V. Contraceptive need among Cambodian refugees in Khao Phlu camp. Int Fam Plann Perspect. 2000;26(4):188-192.

36. Valdes PR, Alarcon AM, Munoz SR. Evaluation of informed choice for contraceptive methods among women attending a family planning program: conceptual development; a case study in Chile. J Clin Epidemiol. 2013;66(3):302-307.

37. Schuler SR, McIntosh EN, Goldstein MC, Pande BR. Barriers to effective family planning in Nepal. Stud Fam Plann. 1985;16(5):260-270.

38. Graham A, Moore L, Sharp D. Provision of emergency contraception in general practice and confidentiality for the under 16's: results of a postal survey by general practitioners in Avon. J Fam Plann Reprod Health Care. 2001;27(4):193-196.

39. Bethea J, Hippisley-Cox J, Coupland C, Pringle M. General practitioner's attitudes towards provision of services to young people aged under 16: a cross-sectional survey. Qual Prim Care. 2007;15(1):11-19.

40. Denny S, Farrant B, Cosgriff J, et al. Access to private and confidential health care among secondary school students in New Zealand. JAdolesc Health. 2012;51(3):285-291.

41. Anand S, Sinha RK. Quality differentials and reproductive health service utilisation determinants in India. Int $J$ Health Qual Assur. 2010;23(8):718-729.

42. Haller DM, Meynard A, Pejic D, et al. YFHS-WHO+ questionnaire: validation of a measure of youth friendly primary care services. J Adolesc Health. 2012;51(5):422-430.

43. Askew I, Mensch B, Adewuyi A. Indicators for measuring the quality of family planning services in Nigeria. Stud Fam Plann. 1994;25(5):268-283.

44. Schoen J. Choice and Coercion: Birth Control, Sterilization, and Abortion in Public Health and Welfare. Chapel Hill, NC: The University of North Carolina Press; 2005.

45. Associated Press. Burmese Muslims given two-child limit. The Guardian, May 25, 2013. Available from: http://www.guardian.co.uk/ world/2013/may/25/burma-muslims-two-child-limit. Accessed July 5, 2013.

46. Johnson CG. (2013, July 7) Female inmates sterilized in California prisons without approval. The Center for Investigative Reporting. Available from: http://cironline.org/reports/female-inmates-sterilized-californiaprisons-without-approval-4917. Accessed November 30, 2014.

47. Contraceptive CHOICE Project (n.d.). Test 3: GATHER Process Observation Form. Available from: http://www.larcfirst.com/resources/ counseling/quality_assurance/Test_3_GATHER_Process_Observation_ Form.pdf. Accessed January 1, 2016.

48. Lawrence RE, Curlin FA. Physicians' beliefs about conscience in medicine: a national survey. Acad Med. 2009;84(9):1276-1282.

49. Borrero S, Schwarz EB, Creinin M, Ibrahim S. The impact of race and ethnicity on receipt of family planning services in the United States. J Womens Health. 2009;18(1):91-96.

50. Downing RA, LaVeist TA, Bullock HE. Intersections of ethnicity and social class in provider advice regarding reproductive health. Am J Public Health. 2007;97(10):1803-1807.

51. Nakhaee N, Mirahmadizadeh AR. Iranian women's perceptions of family-planning services quality: a client-satisfaction survey. Eur $J$ Contracept Reprod Health Care. 2005;10(3):192-198.

52. Entwistle E, Watt IS, Gilhooly K, et al. Assessing patients' participation and quality of decision-making: insights from a study of routine practice in diverse settings. Patient Educ Couns. 2004:55(1):105-113. 
53. Elwyn G, Edwards A, Wensing M, et al. Shared decision making: developing the OPTION scale for measuring patient involvement. Qual Saf Health Care. 2003;12(2):93-99.

54. Kim YM, Kols A, Putjuk F, et al. Participation by clients and nurse midwives in family planning decision making in Indonesia. Patient Educ Couns. 2003;50:295-302.
55. Boydell V, Keesbury J. Social accountability: what are the lessons for improving family planning and reproductive health programs? A review of the literature, Working Paper. Washington, DC: Population Council, Evidence Project; 2014.

\section{Publish your work in this journal}

Open Access Journal of Contraception is an international, peerreviewed, open access, online journal, publishing original research, reports, reviews and commentaries on all areas of contraception. In addition to clinical research, demographics and health-related aspects, the journal welcomes new findings in animal and preclinical studies relating to understanding the biological mechanisms and practical development of new contraceptive agents. The manuscript management system is completely online and includes a very quick and fair peer-review system. Visit http://www.dovepress.com/testimonials.php to read real quotes from published authors. 